\title{
The excretion of two virulent strains of African swine fever virus by domestic pigs
}

\author{
BY A. GREIG AND W. PLOWRIGHT \\ East African Veterinary Research Organization, Muguga, \\ P.O. Kabete, Kenya
}

(Received 30 July 1970)

\section{SUMMARY}

Daily observations were made on the excretion of African swine fever (ASF) virus by pigs infected intranasally or by contact. Two strains of virus having mean death times of approximately 3 and 6 days were used, the latter being recently isolated from a warthog.

First excretion usually occurred by the nasopharyngeal route, as early as 1 or 2 days before the onset of fever in many cases. The titres of pharyngeal and nasal swabs rose rapidly to reach mean levels of about $10^{4}-10^{5}$ HAD 50 at $48-72 \mathrm{hr}$. following the onset of pyrexia. Virus in the secretions of the conjunctiva or lower urogenital tract appeared later and did not attain such high levels. Faecal and urinary excretion was of relatively little significance, except in slower infections caused by the recent warthog virus.

These results are discussed in relation to the known failure of infected pigs to transmit the disease to stallmates during the first 12-24 $\mathrm{hr}$. of pyrexia and also in relation to recent work on the pathogenesis of ASF in domestic swine.

\section{INTRODUCTION}

Little detailed information is available on the routes of excretion of the virus of African swine fever (ASF) by domestic pigs. Montgomery (1921) first demonstrated that the virus is not transferred through the air, in that pigs either separated by 6 in. of wire mesh, or muzzled when in the same pen as a reacting animal, do not acquire the infection. The same worker was able to infect pigs with fresh urine and faeces derived from animals which had recently died from acute ASF. Montgomery also showed that reacting pigs are not infectious to stallmates during the first 12-24 hr. of fever, an observation which has been repeated by Plowright, Parker \& Staple (1968). Scott (1965) suggested that pigs are infected through nuzzling or ingestion of fomites, a hypothesis supported by recent work on the pathogenesis of the disease (Heuschele, 1967; Plowright et al. 1968; Colgrove, Haelterman \& Coggins, 1969).

In order to elucidate the comparative importance of various routes of excretion and to explain why sick pigs are not infectious to others during the first $24 \mathrm{hr}$. of fever, a study was made of the pattern of virus excretion in domestic pigs which had been infected by natural routes with two highly pathogenic strains of virus. 


\section{Virus strains}

\section{MATERIALS AND METHODS}

(a) The Tengani strain caused an epizootic of ASF in Malawi in 1962 (Cox \& Hess, 1962) and was known to cause a rapid lethal disease in domestic swine, the mean death-time being 2.9 days (Plowright et al. 1968). The virus was stored at $-70^{\circ} \mathrm{C}$. in the form of a $10 \%(\mathrm{w} / \mathrm{v})$ spleen suspension which, when titrated in pig bone marrow (PBM) cultures, had a titre of $10^{7 \cdot 4} \mathrm{HAD} \mathrm{50} / \mathrm{ml}$.

(b) The Kirawira virus was recovered in PBM cultures from a warthog shot in the Kirawira Game Control Area, Tanzania, and passaged once in a domestic pig; it was characterized by a longer death-time (mean 7.0 days for 11 pigs). This virus was stored at $-70^{\circ} \mathrm{C}$. in the form of portions of pig spleen which were thawed once only and used to prepare $10 \%(\mathrm{w} / \mathrm{v})$ suspensions in phosphate-buffered saline, pH 7.2 (PBS of Dulbecco \& Vogt, 1954); on PBM assay this tissue had a titre of $10^{7 \cdot 4} \mathrm{HAD} 50 / \mathrm{g}$.

\section{Experimental animals}

Cross-bred, Large White:Landrace pigs of about 40-45 lb. live-weight were reared on the station. They were housed in individual pens in isolation units and their rectal temperature was recorded every morning before the sampling procedures. The 'onset of fever' was usually regarded as occurring on the day when the temperature attained or exceeded $103^{\circ} \mathrm{F}$; this time also marked the end of the incubation period.

\section{Infection of animals}

To initiate the experiments on each virus strain, two groups of two 'donor' pigs were infected by the intranasal instillation of $2 \mathrm{ml}$. of a $10 \%(\mathrm{w} / \mathrm{v})$ spleen suspension while being held in dorsal recumbency. On the third day, when the donors had a rectal temperature $>103^{\circ} \mathrm{F}$., a clean animal was introduced into the same pen and left there for $24 \mathrm{hr}$. before being washed liberally with running water and placed in a clean pen. Recipient pigs, when they reacted, served as donors for further clean animals and the pens were not cleaned out until the pig died.

\section{Samples}

Pigs were examined each morning before being fed, swab samples being taken from: (i) the cheek pouch of the oral cavity, between the cheeks and molar teeth; (ii) the nasal cavity, the swab was inserted 2-3 in. through the external nares; (iii) the pharynx, in the region of the palatal tonsil; (iv) the conjunctiva; (v) the vagina or prepuce, the swab was inserted 1-2 in. into the lumen.

After sampling, the swabs were immediately immersed in $3 \mathrm{ml}$. of complete PBM culture medium (Earle's balanced salt solution with $25 \%$ normal pig serum) containing per ml.: 600 units of penicillin; $600 \mu \mathrm{g}$. of streptomycin; $300 \mu \mathrm{g}$. of kanamycin and 150 units nystatin; the fluid was expressed from the swabs within $1 \mathrm{hr}$. of collection. Faeces samples were collected from the rectum and $10 \%(\mathrm{w} / \mathrm{v})$ 
suspensions were prepared in the above medium; these were centrifuged for $10 \mathrm{~min}$. at $2000 \mathrm{rev} . / \mathrm{min}$. and the supernatant used as inoculum.

Blood samples were taken daily from the anterior vena cava, part being diluted with one-third the final volume of $1.5 \%$ ethylene-diamine-tetraacetic acid:disodium salt (EDTA) in $0.7 \% \mathrm{NaCl}$, whilst the rest was allowed to clot to produce serum for antibody detection.

Urine, when available, was collected at autopsy by aspiration through the bladder wall with a needle and syringe; only pigs infected with the Kirawira virus yielded urine samples. All samples were stored at about $4^{\circ} \mathrm{C}$. before assay in PBM cultures.

\section{Detection and titration of infectivity in samples}

Tenfold dilutions in PBS were prepared from the samples and each dilution was inoculated in a dose of $0.2 \mathrm{ml}$. into five tubes of PBM cells. Undiluted and $10^{-1}$ dilutions of blood were removed after $3 \mathrm{hr}$. incubation at $37^{\circ} \mathrm{C}$. and fresh medium was added to the cells. When the titre was higher than expected, retitrations were carried out from samples stored at $4^{\circ} \mathrm{C}$. for periods of $2-3$ weeks.

\section{Cell cultures and infectivity end-points}

Washed cell suspensions were prepared from the long bones of pigs by the method already described (Plowright et al. 1968). The cells were suspended in medium to a concentration of $7-9 \times 10^{6} / \mathrm{ml}$. and dispensed in $1.6 \mathrm{ml}$. quantities into tubes $150 \times 16 \mathrm{~mm}$., which were incubated for 3-4 days at $37^{\circ} \mathrm{C}$. in stationary racks before inoculation. The medium has been described in the section on 'Samples'; it included a range of antibiotics at one-third the concentration mentioned above.

A final microseopic examination for the haemadsorption and cytopathic effects of ASFV (Malmquist \& Hay, 1960) was carried out on the sixth day after inoculation and end-points, as $\log _{10}$ HAD 50 ( $50 \%$ haemadsorbing doses) per swab, per gram of faeces or per ml. of blood, were calculated by the method of SpearmannKarber (Dougherty, 1964).

\section{Serology}

Agar-gel diffusion precipitation (AGDP) tests and complement fixation (CF) tests were applied to all preinfection sera and to serum samples collected throughout the disease. The AGDP tests were conducted by a slide technique against a concentrated ultrasonic extract of pig kidney cells infected with the 'Uganda' strain of virus (DeTray, 1963). A similar, more dilute extract was employed in the CF test, but normal bovine serum was not included as an enhancing factor (Plowright \& Staple, 1967).

\section{Clinical reaction in pigs}

\section{RESULTS}

The four pigs infected intranasally and eight infected by contact all succumbed to infection with the Tengani strain. The mean incubation periods after intranasal and contact infection were 2.9 and 3.9 days respectively and the mean death-time $2 \cdot 8$ and $3 \cdot 3$ days respectively. 
Using the Kirawira virus the four donors reacted after a mean $3 \cdot 1$ days and nine of ten pigs infected by contact reacted after a mean of 4.4 days; the mean deathtimes were $5 \cdot 7$ and $5 \cdot 8$ days respectively.

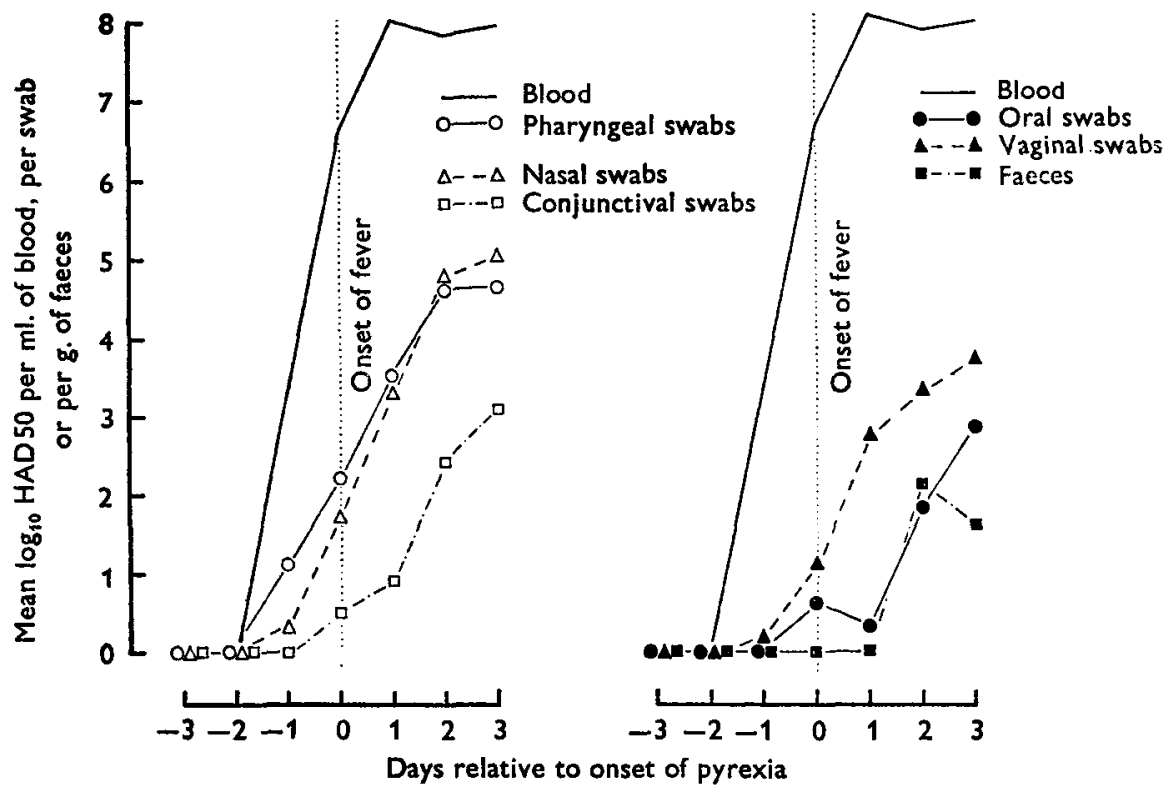

Fig. 1. The excretion of ASFV (strain Tengani) by pigs infected intranasally.

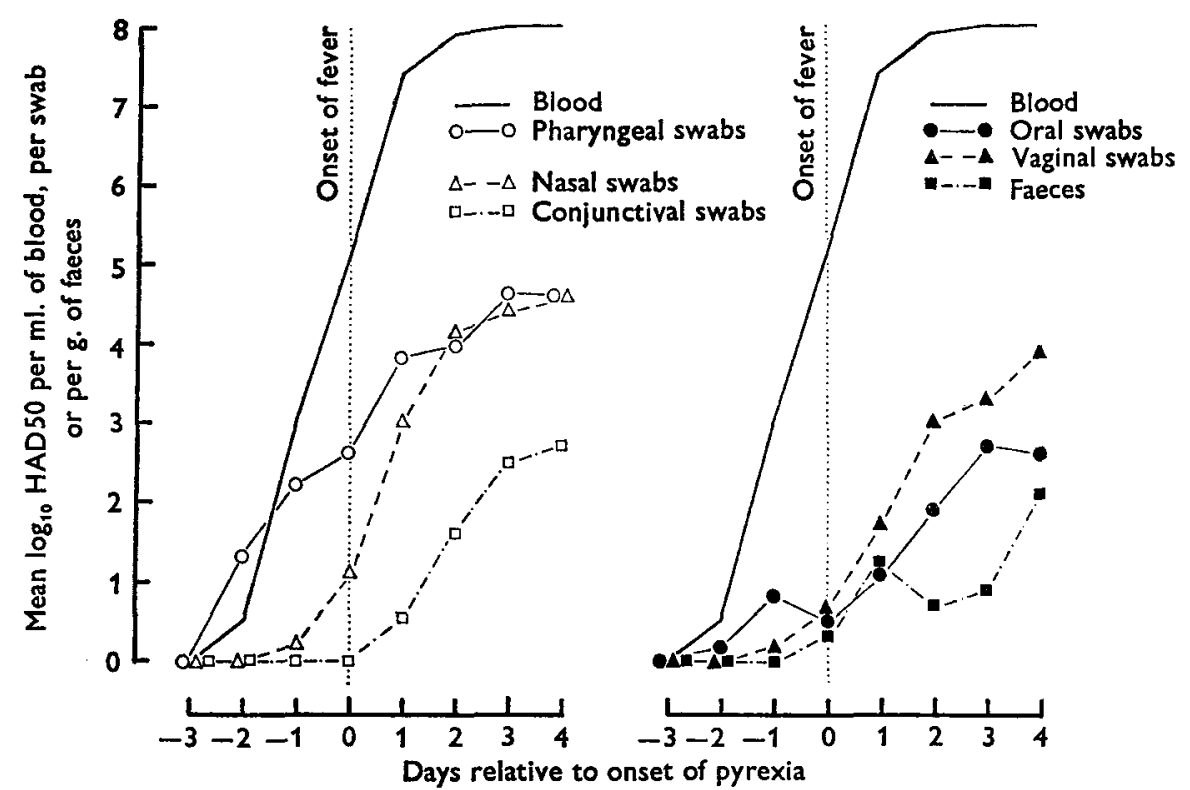

Fig. 2. The excretion of ASFV (strain Tengani) by pigs infected by contact.

The results of titrations of blood and excretions, all expressed as mean figures, are shown in Figs. 1 and 2 for the Tengani strain and Figs. 3 and 4 for the Kirawira (KWH/12) virus. All calculations were made so as to relate virus recovery to the 
onset of fever because it was known that pigs are not infectious during the first $24 \mathrm{hr}$. of pyrexia and it might, therefore, have been assumed that no significant excretion of virus occurs until towards the end of this time. The figures or

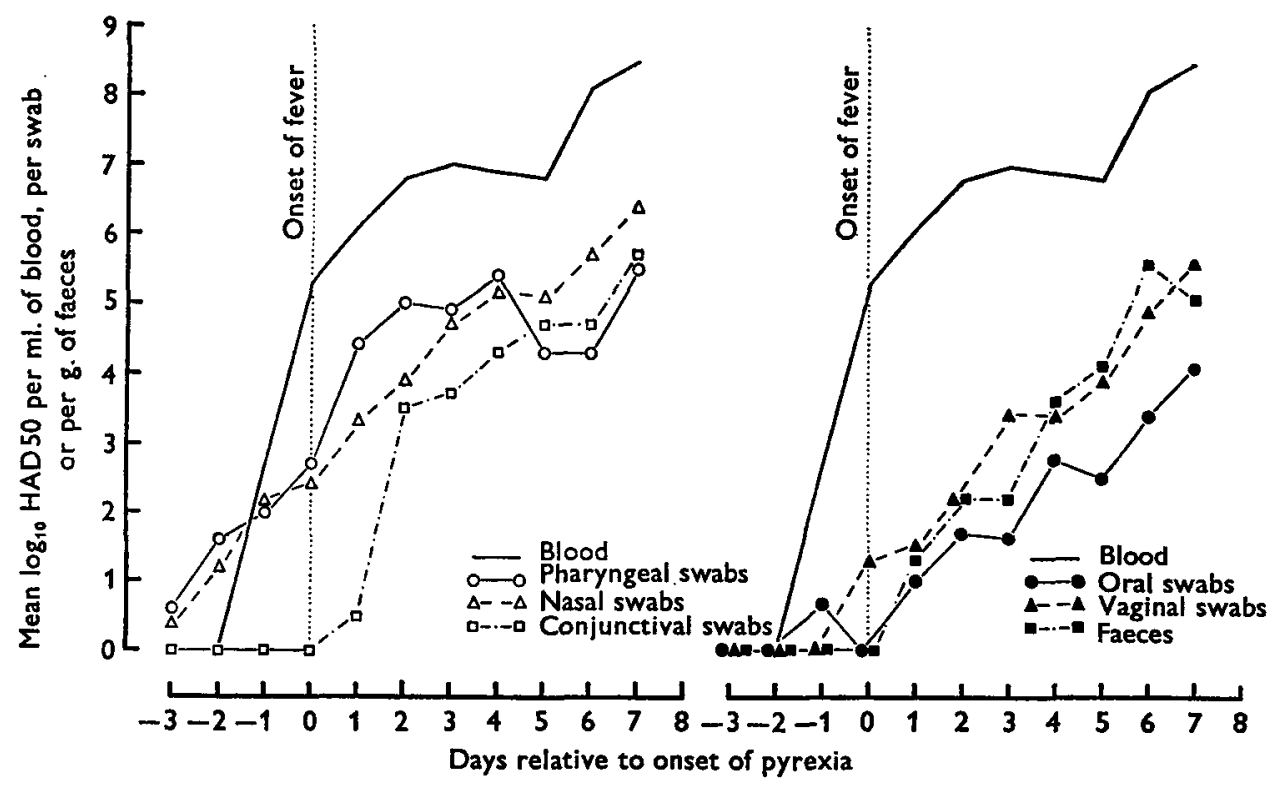

Fig. 3. The excretion of ASFV (strain KWH/12) by pigs infected intranasally.

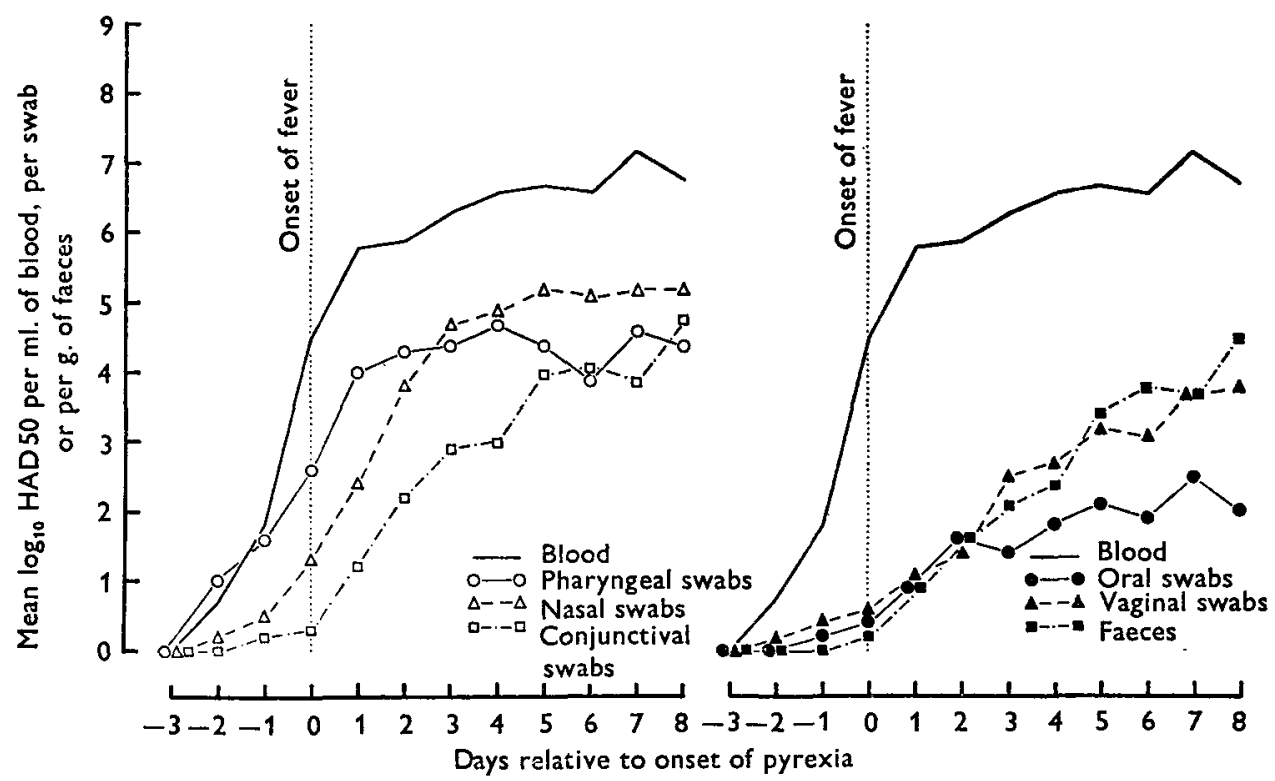

Fig. 4. The excretion of ASFV (strain KWH/12) by pigs infected by contact.

viraemia were used to prepare a reference curve for each group of pigs, indicating the time of generalization and reflecting the level of virus proliferation in the predilection tissues (Plowright et al. 1968; Colgrove et al. 1969). 


\section{Viraemia}

The earliest demonstrable viraemia, 2 days before the onset of fever, occurred in two pigs infected by contact with each strain; all animals, except one Tengani contact case, were viraemic with the onset of fever. At this time blood titres for the Tengani strain varied from $10^{2 \cdot 0}$ to $10^{8 \cdot 2} \mathrm{HAD} 50 / \mathrm{ml}$, whereas for the Kirawira virus they were in the range $10^{2 \cdot 2}$ to $10^{6 \cdot 6} \mathrm{HAD} 50 / \mathrm{ml}$. An examination of the viraemia curves in Figs. 1 and 2 shows that circulating Tengani virus increased rapidly and logarithmically to reach a plateau of about $10^{8}$ HAD 50 on the second and third days of fever. The $\mathrm{KWH} / 12$ virus, on the other hand, proliferated less rapidly and mean viraemia levels increased gradually throughout the course of the disease; maximum mean titres were about $10^{7} \mathrm{HAD} 50 / \mathrm{ml}$. in animals infected by contact and $10^{8 \cdot 5}$ terminally in pigs inoculated intranasally (Figs. 3, 4).

\section{Pharyngeal excretion}

Figs. 1-4 show clearly that excretion of both strains of virus by the pharyngeal route occurred earlier and, except in the terminal stages of the disease, to higher titre than by any other pathway. Later, nasal swabs may well have included much virus derived from the nasopharynx but accumulating in the nasal passages and thus resulting in mean titres exceeding those of pharyngeal swabs.

Pharyngeal swabs first contained Kirawira virus on the third day preceding the onset of fever; this was from a single animal infected by the intranasal route. Approximately half of all the pigs infected with both strains excreted virus on the second day before pyrexia and, with the exception of one Tengani donor which excreted virus on the second day, all yielded positive swabs on the first day of fever. The quantity of virus recovered from single pharyngeal swabs varied between $10^{0 \cdot 9}$ and $10^{5 \cdot 1}$ HAD 50 up to and including the onset of pyrexia. The mean titre continued to increase up to the second or third day of fever and then maintained constant high levels, between about $10^{4}$ and $10^{5}$ HAD 50/swab, until death (Figs. 1-4). The titre of individual swabs also varied widely during the clinical disease, from $10^{0 \cdot 9}$ to $10^{6 \cdot 3}$ HAD 50 .

\section{Nasal excretion}

Generally speaking, the recovery of ASFV from nasal swabs followed closely the pattern established for pharyngeal excretion. The relative delay in nasal excretion was more clearly evident in pigs infected by contact (cf. Figs. 2 and 4 with 1 and 3). A small quantity of virus was recovered on the day following inoculation from one of four pigs infected intranasally with the Kirawira strain; this was 3 days before the onset of fever. All of these four pigs showed virus in the nasal secretions on the day preceding first pyrexia, the titre of swabs up to this time varying from $10^{0 \cdot 9}$ to $10^{3 \cdot 1} \mathrm{HAD} 50$. Thereafter, the recovery of virus from single swabs varied from $10^{1 \cdot 7}$ to $10^{7 \cdot 1}$ with a progressive rise to death in mean values (Fig.3).

Nasal excretion of the Tengani strain was relatively delayed in pigs infected intranasally; only one of four pigs yielded a positive swab on the day preceding fever and all did not become positive until the second day of pyrexia. Virus titres 
up to and including the first day of fever were comparable with those for the Kirawira virus.

Only one of eight animals infected by contact with the Tengani strain excreted virus by the nasal route on the day preceding fever; the behaviour of the Kirawira virus was comparable, two of nine pigs being positive at this time. About half the pigs $(8 / 17)$ were nasal excretors on the first day of pyrexia, with virus titres up to this time ranging from $10^{0.9}$ to $10^{3 \cdot 9} \mathrm{HAD} 50 / \mathrm{swab}$. All animals had become positive by the third day of fever and from this day onwards the quantity of virus in individual swabs ranged between $10^{2 \cdot 9}$ and $10^{5 \cdot 7}$ for the Tengani strain, and $10^{2 \cdot 6}$ to $10^{6 \cdot 3}$ HAD 50 for the Kirawira virus.

\section{Conjunctival excretion}

Figs. 1-4 show clearly that conjunctival excretion of ASFV first occurred 1-3 days later than by the nasopharyngeal route. It is also evident that, on average, the quantity of virus excreted by this means was considerably smaller during Tengani-strain infections than in the longer course of the disease induced by the $\mathrm{KWH} / 12$ virus. On and after the 5th day of clinical infection with the latter, conjunctival excretion was roughly equivalent to pharyngeal release of virus.

Conjunctival excretion of Tengani virus did not begin until the first or second days of pyrexia, in animals infected intranasally and by contact respectively; nine of twelve animals were positive by the third day of pyrexia and ten of eleven by the fourth. The mean titre of swabs increased progressively during the disease but there was considerable variation throughout, from $10^{0.9}$ to $10^{5 \cdot 1} \mathrm{HAD} 50 / \mathrm{swab}$. The Kirawira virus appeared in the conjunctival swabs of all 13 pigs by the fourth day of the disease, a single isolation being recorded from a contact-infected animal on the first day of pyrexia. Titres of individual swabs again showed a very wide variation, from $10^{1 \cdot 1}$ to $10^{6 \cdot 1}$ HAD 50 .

\section{Oral excretion}

Excretion of both strains of ASFV by the oral route was erratic and at a low level. Three of 17 pigs infected by contact yielded virus in oral swabs on the day preceding pyrexia, but consistent excretion by this route only occurred in the terminal stages of the disease; two of eleven pigs infected with the Tengani strain were positive on the third day of fever and 12 or 13 infected with the Kirawira virus by the sixth day of pyrexia. The amount of virus in individual swabs varied from $10^{0 \cdot 9}$ to $10^{4 \cdot 9}$ HAD 50; only five specimens had titres $>10^{4 \cdot 0}$.

\section{Excretion from the lower urogenital tract}

The lower urogenital tract was of relatively greater importance than the oral route in the excretion of ASFV; a reference to Figs. 1-4 shows that it was comparable in importance to the conjunctival secretion.

Two animals infected with each strain revealed virus in the prefebrile period with individual titres up to $10^{3 \cdot 2}$ HAD 50 being recorded. All pigs infected by contact with the Tengani strain were positive by the third day of pyrexia but this situation was not reached until the seventh day in the case of the Kirawira virus. 
After the onset of fever the titres of single swabs varied from $10^{1 \cdot 5}$ to $10^{5 \cdot 5}$ and $10^{0 \cdot 9}$ to $10^{5 \cdot 3}$ HAD 50 respectively for the two viruses. The mean titres rose progressively throughout the clinical disease to exceed $10^{3 \cdot 5}$ terminally for the Kirawira virus (Figs. 3, 4).

\section{Faecal excretion}

The figures for this route were incomplete owing to difficulties in collecting faeces in the terminal stages of the disease.

Pigs infected with the Tengani strain excreted little virus in the faeces and then in an irregular and delayed manner; virus was first detected in two 'contact' animals at the onset of fever but two of this group and one infected intranasally never became positive.

In comparison, animals infected by contact with the Kirawira virus excreted ASFV in the faeces from the first day of fever onwards but all pigs did not become positive until the sixth day; all four animals infected intranasally were faecal excretors by the third day of pyrexia. The quantity of virus in the faeces varied for this strain from $10^{1 \cdot 4}$ to $10^{5 \cdot 8} \mathrm{HAD} 50 / \mathrm{g}$., the mean titres later in the disease exceeding those for the Tengani virus by 2 to $2.5 \log _{10}$ units.

\section{Urinary excretion}

Since animals dying after infection with the Tengani strain almost invariably had an empty, contracted bladder, no figures were obtained for this virus. Three of four Kirawira 'donors' had ASFV in the urine at death, with titres varying between $10^{3.0}$ and $10^{5 \cdot 0} \mathrm{HAD} 50 / \mathrm{ml}$; six of nine animals infected by contact also had virus in the urine, varying in quantity from $10^{0.8}$ to $10^{4 \cdot 2} \mathrm{HAD} 50 / \mathrm{ml}$.

\section{The antibody reaction in acute $A S F$}

No precipitating or complement-fixing antibodies were detected in serum samples collected throughout the course of the disease.

\section{DISCUSSION}

The results reported in this paper show unequivocally that two strains of ASFV were excreted by many infected pigs 1 or 2 days before the onset of fever, particularly by the nasopharyngeal route. It is necessary to remark, however, that all pigs did not become excretors of detectable amounts of virus until the second day of pyrexia, i.e. at least $24 \mathrm{hr}$. after the onset of fever. It was also evident that the quantity of virus excreted, reflected here in the mean titre of swabs, usually remained small during the first day of the clinical reaction. Failure of the virus to spread to susceptible pigs in close contact with infected animals during their first 12-24 hr. of pyrexia must, therefore, be due to inadequate degrees of contamination of the environment, including food and water, rather than the absence of virus excretion, as suggested by Plowright et al. (1968). The dose of ASFV necessary to infect pigs by natural routes has not been determined accurately, but Heuschele (1967) quoted Maurer et al. (1954, unpublished results) as showing that at least $10^{5-0}$ parenteral ID50 of pig-tissue virus were necessary to infect pigs 
orally. Using warthog-tissue virus, Plowright, Parker \& Peirce (1969) found that $10^{6 \cdot 1}$ HAD 50 did not infect orally, whereas doses of about $10^{3}$ to $10^{4}$ HAD 50 did infect a proportion of pigs when administered intranasally.

The early recovery of ASFV from the nasopharynx of naturally infected pigs supports the eontention of several groups of workers that first proliferation of virus commonly occurs in the pharyngeal area, either the palatal tonsil (Heuschele, 1967; Colgrove et al. 1969; A. Greig, to be published) or the retropharyngeal mucosa (Plowright et al. 1968). Virus in oral swabs can also possibly be regarded as arising from the pharyngeal area, since there are very seldom macroscopic lesions of the mouth epithelia in ASF and the amount of virus in the oral cavity was consistently lower than that in the pharynx.

As already observed, virus in the nasal cavities may well have been derived, at least partially, from the nasopharynx. In addition, there can be little doubt that oedema fluid or froth from the trachea and bronchi, which sometimes appears at the nostrils in the terminal stages of the disease, could also contribute to the virus recovered from both the pharyngeal and nasal cavities; the titre of lung tissue in acute ASF due to the Tengani strain of virus is commonly greater than $10^{7} \mathrm{ID} 50 / \mathrm{g}$. (Plowright et al. 1968; Colgrove et al. 1969), whilst interstitial and alveolar oedema are frequent gross lesions.

Whereas the major source of contamination of the environment is the nasopharynx in the early course of the infection, conjunctival and genital discharges may contribute significantly at a later stage, particularly in more prolonged forms of the disease, as produced by recent warthog viruses. Our data on virus in the urine are incomplete but do not suggest that large quantities of virus are excreted by this route, in spite of the fact that considerable numbers of petechial or larger haemorrhages are usually present in the cortex, medulla and pelvis of the kidneys, as well as less frequently in the urinary bladder. It is, therefore, surprising to note that Montgomery (1921) had no difficulty in infecting pigs with fresh urine administered orally.

Very small quantities of virus were excreted in the faeces of pigs infected with the Tengani strain of ASFV and high mean levels ( $>10^{4} \mathrm{HAD} 50 / \mathrm{g}$.) were not attained in animals infected by the Kirawira virus until the last day or two preceding death. The first observation is in keeping with the fact that the mean titres of the washed mucosae of the small and large intestines of pigs infected with the Tengani virus were always one or two $\log _{10}$ units lower than those of the blood at the same time (Plowright et al. 1968). The later rise of faecal titres in pigs infected with a 'slower' strain of virus may have been a result of the release into the faeces of high-titre blood from haemorrhages in the intestinal mucosae. Diarrhoea and dysentery was sometimes observed in advanced cases of the disease and in these the total quantity of virus excreted in the faeces must have been very considerable.

We are grateful to Messrs C. T. Perry, W. J. Doughty, R. W. Kapaata, H. Agili and D. Waweru for their able technical assistance, and to Mr C. S. Rampton who produced the Figures. 


\section{REFERENCES}

Colgrove, G. S., Haflterman, E. O. \& Coggins, L. (1969). Pathogenesis of African swine fever in young pigs. American Journal of Veterinary Research 30, 1343-59.

Cox, B. F. \& Hess, W. R. (1962). Note on an African swine fever investigation in Nyasaland. Bulletin of Epizootic Diseases of Africa 10, 439-40.

DeTray, D. E. (1963). African swine fever. Advances in Veterinary Science 8, 299-333.

DougherTy, R. M. (1964). In Techniques in Experimental Virology, Ed. R. C. J. Harris. Academic Press.

Dulbecco, R. \& Vogt, M. (1954). Plaque formation and isolation of pure lines of poliomyelitis viruses. Journal of Experimental Medicine 99, 167-82.

HeUschele, W. P. (1967). Studies on the pathogenesis of African swine fever. Archiv für die gesamte Virusforschung 21, 349-56.

Malmquist, W. A. \& Hay, D. (1960). Hemadsorption and cytopathic effect produced by African swine fever virus in swine bone marrow and buffy coat cultures. American Journal of Veterinary Research 21, 104-8.

Montgomery, R. E. (1921). On a form of swine fever occurring in British East Africa (Kenya Colony). Journal of Comparative Pathology and Therapeutics 34, 159-91.

Plowright, W., Parker, J. \& Peirce, M. A. (1969). The epizootiology of African swine fever in Africa. Veterinary Record 85, 668-74.

Plowright, W., Parker, J. \& Staple, R. F. (1968). The growth of a virulent strain of African swine fever virus in domestic pigs. Journal of Hygiene 66, 117-34.

Plowright, W. \& Staple, R.F. (1967). East African Veterinary Research Organization Annual Report, 1967, p. 12. East African Community, Arusha, Tanzania.

ScotT, G. R. (1965). African swine fever virus. Veterinary Record 77, 1421-7. 